\title{
STAYING POWER
}

\section{Carving out a successful career as an academic is hard, but there are steps you can take to ease your way.}

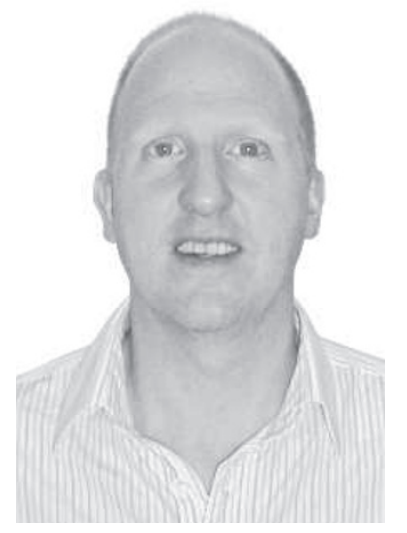

Moray Campbell
The odds of progressing from being a $\mathrm{PhD}$ student to holding a faculty post are at least 100:1. For those who manage to make the move, their future success will hinge on them working on the right research question at the right time and in the right place. And on top of that, they should also be helping their employer's organization to evolve.

One person rarely meets these criteria indefinitely at a single institution. As a result, people need to be aware of their 'institutional shelf-lives' and should see their host institute as just a sub-network in the larger academic landscape in which individuals, ideas and resources flow freely. Fortunately, unlike most industries, there are several indicators that can be used to measure performance - from publications and grant income to teaching revenue and student feedback. And these can aid researchers in their quest for mobility.

Scientists in the early stages of their career rarely achieve success in all of the performance criteria, so the decision of an appointment panel for a post tends to be based on current research attainment and future potential.

The challenge of succeeding in a post is compounded by the

"For most people
in academia, the
overwhelming
experience is
rejection - most
commonly of
grants and
manuscripts."
current trend for consolidation in the academic sector. In several European countries, including Denmark and Britain, institutions are merging as if they were multinational companies. Such conditions make career strategy even more crucial - and there are some basic rules you should consider.

Faced by a charging grizzly bear, you have only to run faster than your neighbour All selection committees focus on publications - as much for potential as for current achievement. So postdocs and graduate students need to finish and submit papers before they hit the job market, and should be proactive about the order of author names on their papers. But to stand out, you'll need something extra, such as being active in local, national and international organizations, having supervisory experience or a teaching role. And think carefully about the choice of referees you use on your CV or résumé. These must include your current principal investigator, but if you can offer external and international scientists, it will suggest that you have an interactive and outgoing nature.

Once in post, the same skills and mind-set will sustain you. In my case, I continued training undergraduate scientists and ensured that my graduate students received the best training I could facilitate, including training visits to the labs of more senior collaborators. Joining small projects together develops more cohesive bodies of work to attract larger grants and sustain publications. Exclusive focus on research can be a vulnerable position, and combining that with teaching and administrative duties will justify promotion. Alone, none of these steps is dramatic. But together they generate a broad portfolio.

\section{Avoid dynasties}

The trick is to pick up new skills and insights while moving through your PhD and postdoc positions. $\mathrm{PhD}$ training develops generic skills, such as how to handle pressure or how to write. Ideally, a PhD student should experience how to release their innate creativity. Postdoc work develops greater intellectual and research skills combined with the ability to supervise others. Repeating your principal investigator's ideas, or remaining in their sphere of influence too long, will nearly always make it harder for you to be recognized for your achievements, leading to stunted intellectual and career development, and frustration. Ironically, gaining independence can be made more fraught by some principal investigators' 'king-maker' tendencies.

\section{Travel broadens the mind}

Mobility stimulates novel approaches and insight, so recruiting committees tend to want candidates with diverse training backgrounds, and often mistrust 'home-grown' talent. The desire for international exposure, although it can be over-hyped, can also be beneficially exploited by following the money abroad, succeeding in a new country and then seeking out opportunities offered by repatriation schemes. Mobility doesn't finish with a faculty appointment; I have reached my institutional shelflife here and, after about ten years in Britain, I am ready to return to the United States.

\section{Sometimes you're ahead, sometimes behind, but in the end the race is with yourself} For most people in academia, the overwhelming experience is rejection - most commonly of grants and manuscripts. So you should examine your career motivations carefully. Find and use mentors locally, nationally and internationally to test your ideas. Remember to take on reviewers' feedback no matter how negative and provocative (if they didn't understand your grant, it may be because you didn't take time to write it clearly).

I am trying to follow my own advice. My goals now are to get my work published in some top journals, take up a position in the United States - and then plan my next move. University of Birmingham, UK. 